\title{
INTRODUCTION TO THE EXAMINATION OF THIN-WALLED STRUCTURES USING THE VIBRODIAGNOSTIC METHOD
}

\author{
Adam Szeleziński, Adam Muc, Lech Murawski, Do Van Doan \\ Gdynia Maritime University \\ Faculty of Marine Engineering \\ Morska Street 83-87, 81-225 Gdynia, Poland \\ tel.: +48585586331 \\ e-mail:a.szelezinski@wm.umg.edu.pl,a.muc@we.umg.edu.pl \\ l.murawski@wm.umg.edu.pl,dodoan.vimaru@gmail.com
}

\begin{abstract}
The article presents a methodology of non-destructive diagnostic vibratory tests of welded plates with geometrical parameters that classify them into a group of thin-walled panels. On the basis of such plates, most ship constructions are created. In previous works, the authors dealt with the study of welded joints in plates with significant thicknesses and developed for them a number of methods for assessing the quality of welded joints. Vibrodiagnostics is a NDT method that allows the use of a variety of techniques and tools. It enables measurements to be made in both a contact and non-contact way depending on the requirements of the structure and the environment. Vibrodiagnostic method is one of the most modern NDT methods, which uses modern measurement tools and computer analysis of data. On the basis of the developed methods, the authors intend to verify their application to plates from real welded constructions, which will be performed in typical shipyard conditions by welders. Such tests are important due to their use for the construction of a real SHM ship construction monitoring system. These methods allow for the examination of the condition of ships' structural plates and can detect defects in welded joints that prevent ships from operating under severe sea conditions. The article presents the laboratory stand, the sensor layout, results, and their initial analysis.
\end{abstract}

Keywords: welding, welded joints, non-destructive testing, vibrations, time-frequency characteristics

\section{Introduction}

After getting promising results for the significant thickness panels, seven plating sheets with a smaller relative thickness were examined. The thick panels have been tested under laboratory conditions. All welds in the new plates were made by welders with qualifications and under shipyard working conditions, so objects occurring in industrial practice were examined. The idea of this article was to prepare for further analysis of sheets of different dimensions and state of welds than in the first stage of research which was widely described in $[6,12]$. Two methods were used for the preliminary assessment of welded joints in thin plates in order to be able to confront the results. The first method is the analysis of the own frequencies of plates, which is based on the frequency analysis of responses recorded for individual accelerometers placed on plates. The second method is a graphical representation of time and frequency dependencies, which have already been described in the paper $[2,10]$. In the papers $[3,9,14]$ the most important terms related to the application of vibration tests to the assessment of welded joints were defined. In particular, the place of vibration testing among other studies used in NDT techniques (Non-Destruction Testing) was described. It also indicates the advantages and disadvantages of new and old NDT methods. In the diagnosis of marine structures NDT, testing is extremely important for many reasons. This aspect has been widely described in the papers $[4,7,8]$. NDT testing methods are also widely used in real-time structural monitoring systems. Such systems are referred to as SHM (Structural Health Monitoring). Real-time structural monitoring systems seem to be the future of modern diagnostics of mechanical structures exposed to the aggressive environment of their exploitation. 


\section{Preliminary examinations of metal sheets used in thin-walled constructions}

The tested plates are similar in size to real objects. A smaller relative thickness of the plate has an impact on the change of its dynamic characteristics and may affect the sensitivity of the developed diagnostic measures. It is also important that the tested plates were made by professional welders and the resulting damage was not an intentional action. Some of the tested plates have defective welds, which were negatively verified using commercial NDT techniques at one of the Pomeranian shipyards. The plates used in the tests in the papers [12] were $350 \times 250 \times 15 \mathrm{~mm}$, whereas the plates used in the described tests were $500 \times 500 \times 4 \mathrm{~mm}$. Already described apparatus [13] was used during the tests. The transducers were mounted according to the scheme shown in Fig. 1. Unlike to the testing of thick plates, for real-life applications three piezoelectric sensors, ACC1, ACC2 and ACC3, were used with an additional sensor marked as ACC2.

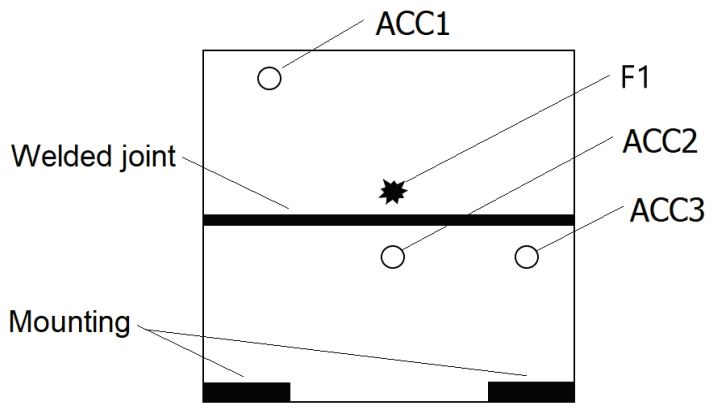

Fig. 1. Arrangement of transducers during the second series of tests. ACC1-Accelerometer (Channel 1-Up) ACC2 - Accelerometer (Channel 2 - Down), ACC3 - Accelerometer (Channel 3 -Down Right)

F1 - Modal hammer impact location

During the tests, the plate displacement was also recorded with the use of laser sensors. Vibration displacement amplitudes derived from laser sensors provide more diagnostic information for low frequencies compared to acceleration amplitudes derived from accelerometers. In the case of the analysed structure, the use of acceleration sensors is more advantageous, also due to the practical possibilities of their application in autonomous SHM systems. The application of several or several dozen-laser sensors in the SHM system would be extremely difficult for both technical and economic reasons. Based on the analysis of the modal hammer tip type's influence on the quality of conducted research, only the metal tip was used at this stage of the research.

The use of a metal tipped modal hammer, compatible with the measuring system, has allowed the exact measurement of the induced force, an example of which is shown in Fig. 2.

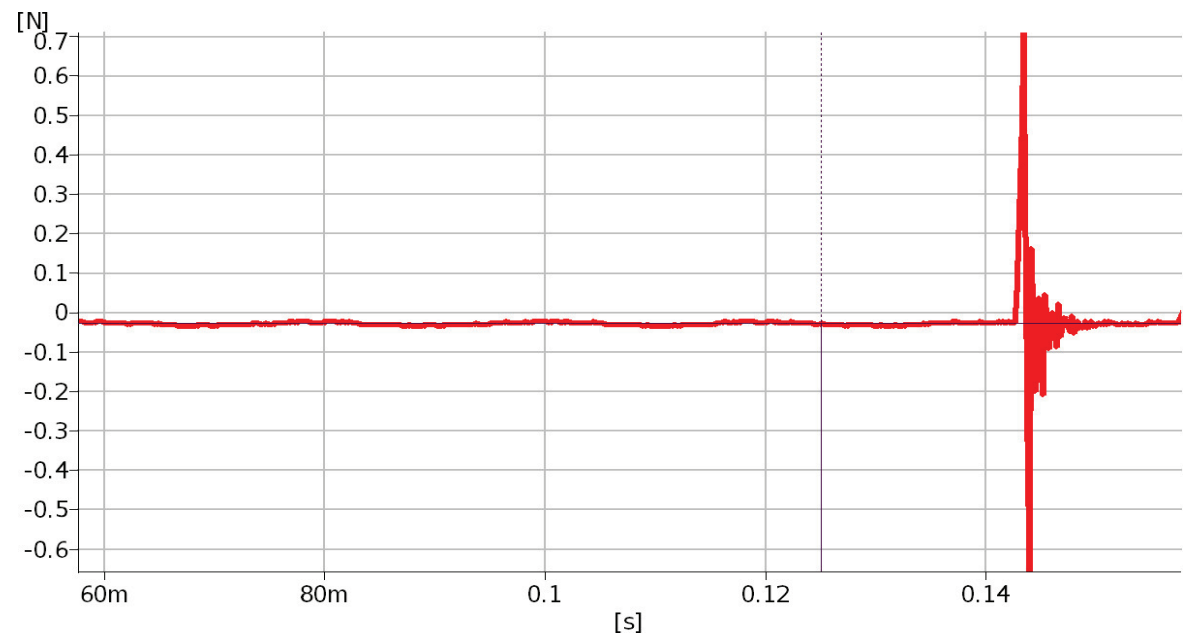

Fig. 2. Time sequence of the inducement force value recorded by the force sensor in the modal hammer 
Vibration parameters obtained as a result of measurements carried out on seven plates with different weld conditions were analysed. It should be noted here that welded joints were performed by professional welders and their condition reflects typical weld conditions. Most of the joints selected are those with non-approved welded joints. Made joints were evaluated using radiographic method. The following types of defects have been detected in welds:

- P1 plate - plate without welded joint,

- P2 plate - no melting,

- P3 plate - few spherical blisters, the connection is considered good,

- P4 plate - no melting,

- P5 plate - no melting,

- P6 plate - no melting, edge adhesion, longitudinal blister,

- P7 plate - no melting, edge adhesion, longitudinal blister.

All tests were carried out in accordance with the principles of good practice. These include the calibration of the apparatus used. The calibration procedure is described in more detail in the paper $[1,5]$. The repeatability of the obtained results was checked. For this purpose, the dynamic characteristics of the tested objects, which were obtained by multiple excitation of vibrations with different inducement forces, were compared. Lack of repeatability could indicate improper mounting of the test object or errors in the processing of the measurement signal.

The comparison of P1 plate spectra for the next 10 impacts with a modal hammer is shown in Fig. 3. In Fig. 4 there is a similar comparison, but for plate P3.

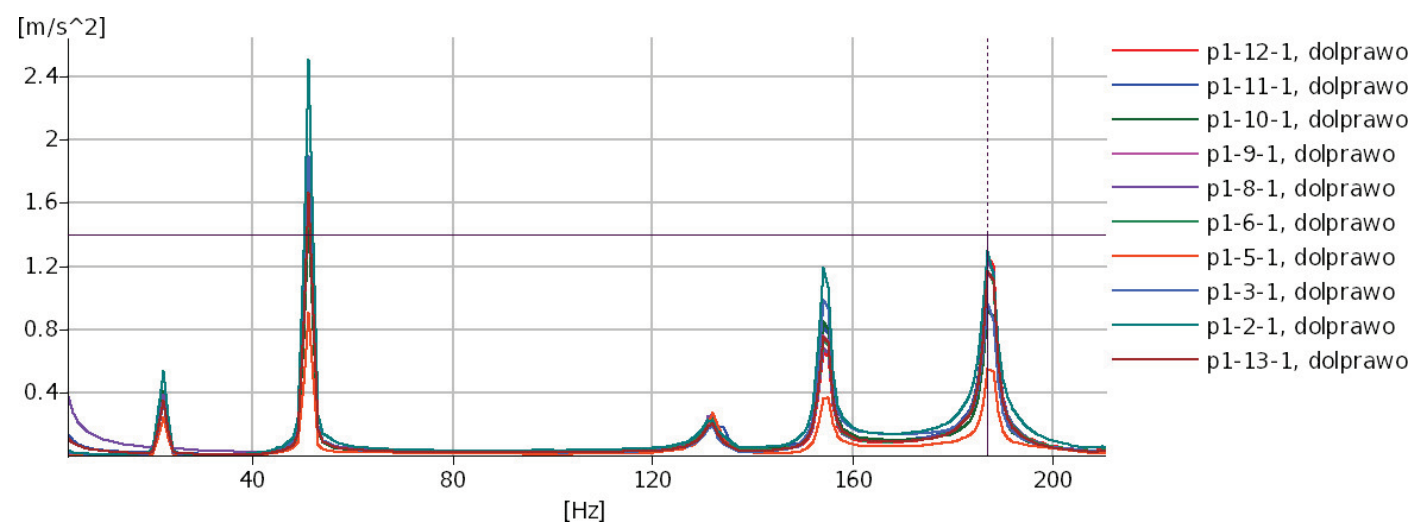

Fig. 3. The vibration acceleration spectra of response to modal hammer impact for 10 consecutive impacts of P1 plate

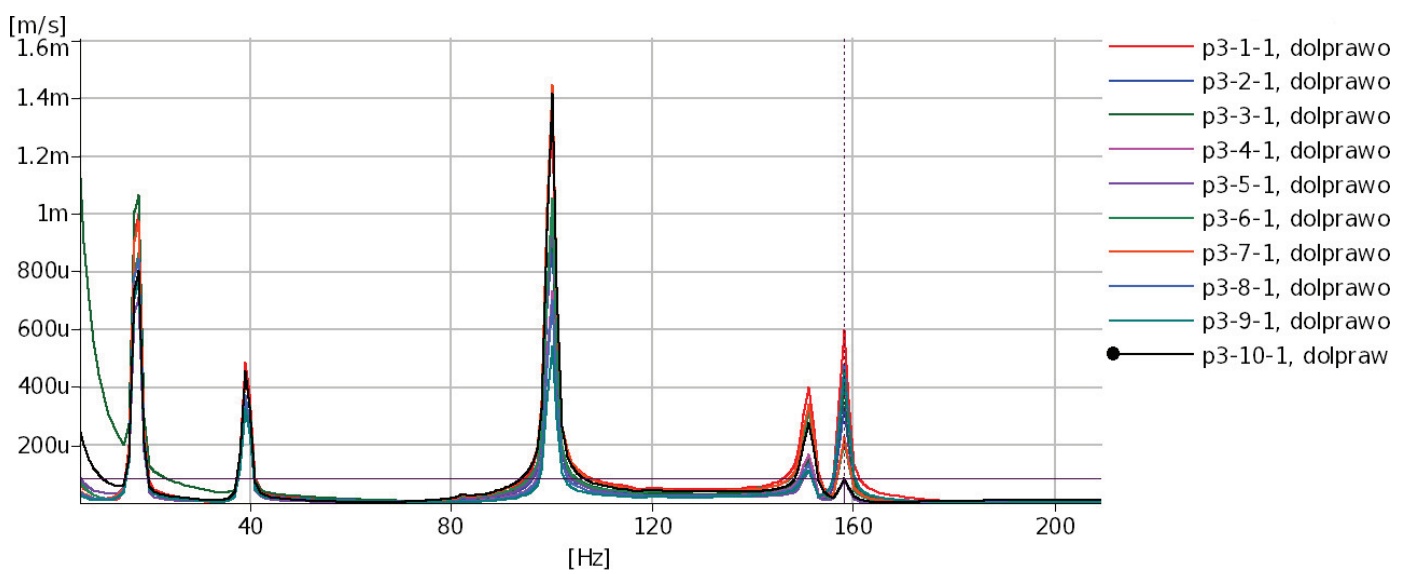

Fig. 4. The vibration acceleration spectra of response to modal hammer impact for 10 consecutive impacts at P1 plate

Figure 3 shows the approximation of the spectra for the P1 plate. It made possible to read the values of the plate's own vibration form without a welded joint. This are: $22 \mathrm{~Hz}, 51 \mathrm{~Hz}, 132 \mathrm{~Hz}$, $154 \mathrm{~Hz}$ and $187 \mathrm{~Hz}$. The values of frequencies of further forms were not figured, because under 
normal operating conditions there are no excitations of such high frequencies. The frequencies of own vibration of plate with a welded joint which can be considered correct (P3) are as indicated in Fig. 4 respectively: $18 \mathrm{~Hz}, 39 \mathrm{~Hz}, 100 \mathrm{~Hz}, 151 \mathrm{~Hz}$ and $158 \mathrm{~Hz}$.

Figure 5 shows the spectra for 10 consecutive impacts recorded for a P7 plate with significant defects. The frequency values read from the spectra in the diagram in Fig. 5 of P7 board are respectively: $39 \mathrm{~Hz}, 97 \mathrm{~Hz}$ and $157 \mathrm{~Hz}$.

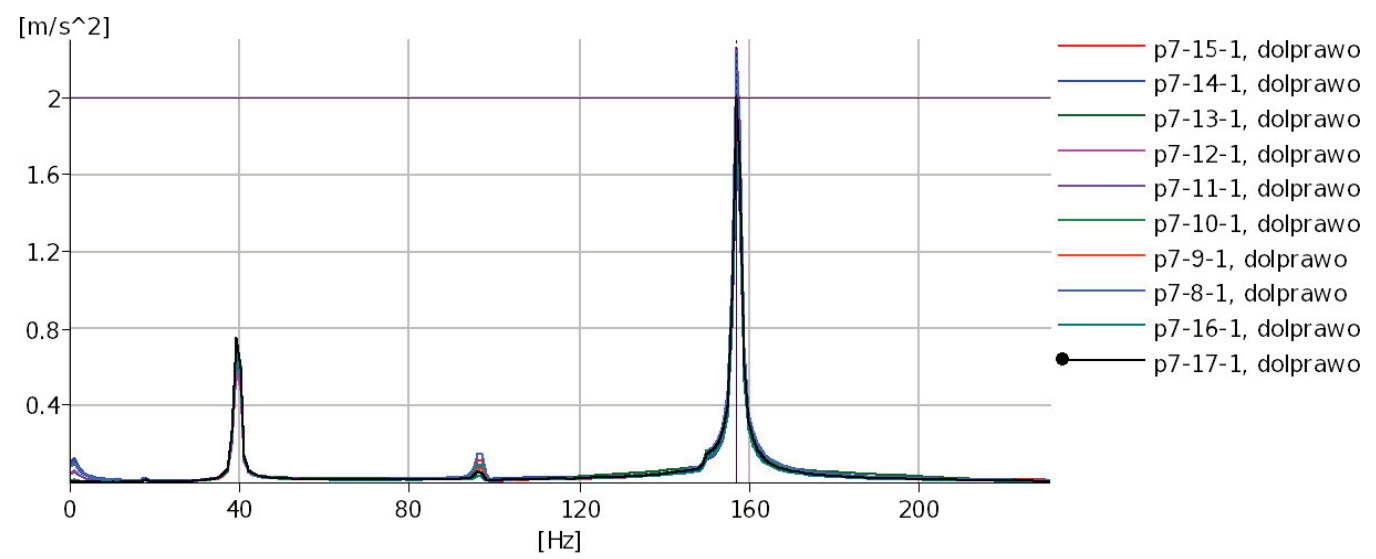

Fig. 5. Approximation of vibration acceleration spectra of response to modal hammer impact for 10 consecutive impacts at $P 7$ plate

Therefore, the influence of the occurrence of the weld and its condition on the values of the own frequency of vibrations as well as on the values of the response amplitude is visible. This effect is also illustrated by the spectra in Fig. 6. Fig. 6 shows a comparison of the spectra obtained during the examination of all the plates.

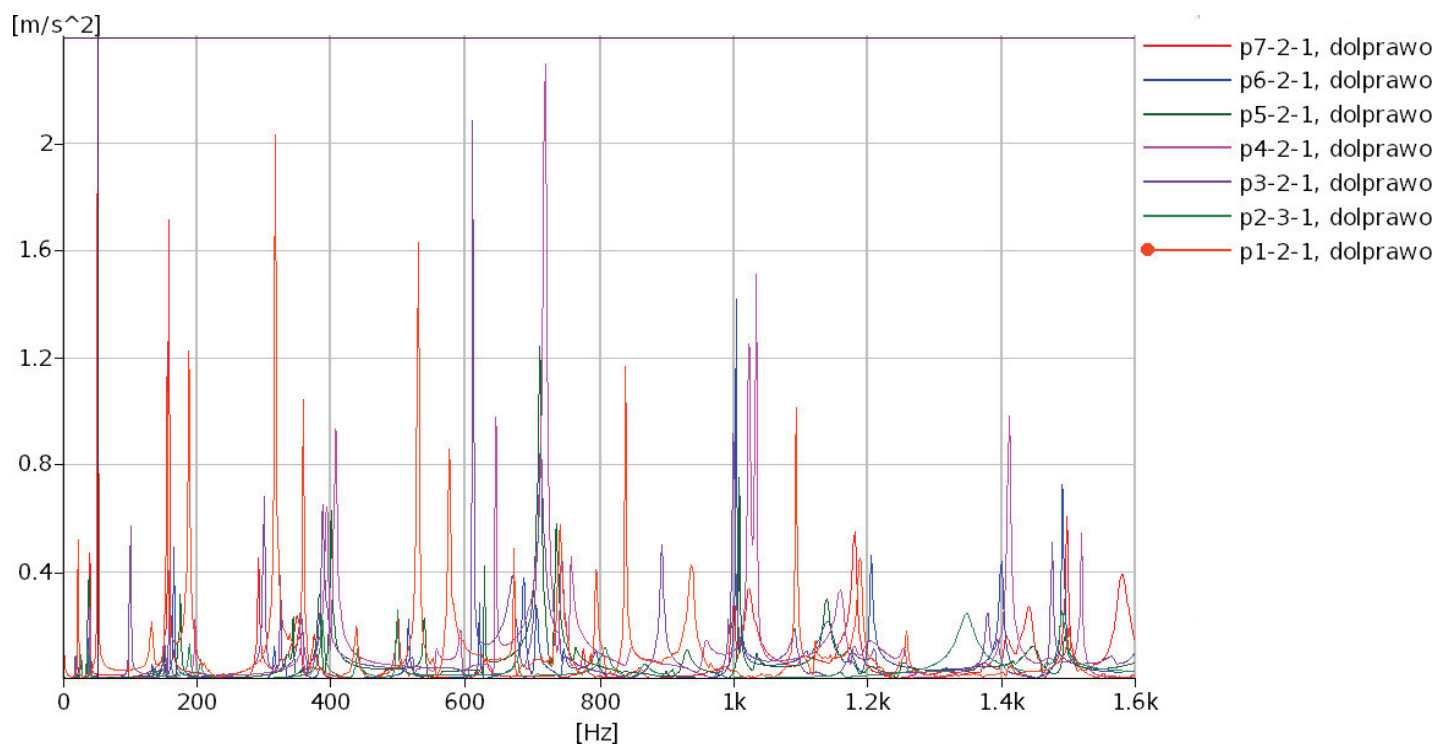

Fig. 6. Comparison of vibration acceleration spectra of all tested plates

This comparison, made in B\&K's Pulse Reflex program, gives grounds to conclude that the tests were performed correctly. Such a conclusion can be drawn from the analysis in the frequency domain, where in Fig. 3 all waveforms have compatible frequencies of the dominant amplitudes. In Figs. 4, 5 and collectively in Fig. 6 we can observe the influence of weld defect on the frequency characteristics of the tested plates - despite the identical method of mounting the plates and the identical method of testing. This situation results from the different state of welds in the tested plates, and consequently from different resonance responses. After obtaining the expected 
results of the verification of the measurement data, the author proceeded to the realization of the basic stage of the research, which consisted in applying the time and frequency analysis in the graphic form to the tested plates.

\section{Analysis of 2D and 3D time-frequency characteristics}

The method of analysing the 2D and 3D time and frequency characteristics of welded plates was described in the papers $[2,10]$. As a result of analyses of the obtained characteristics, it was found that the time of disappearance of significant components in the case of the tested plates, characterized by a smaller thickness, is much longer than in the case of the previously tested plates of considerable thickness. This indicates lower damping of this type of plates. The set of timefrequency characteristics for the plate (P1) is shown in Fig. 7, for the plate P3 in Fig. 8 and for the plate (P6) in Fig. 9.

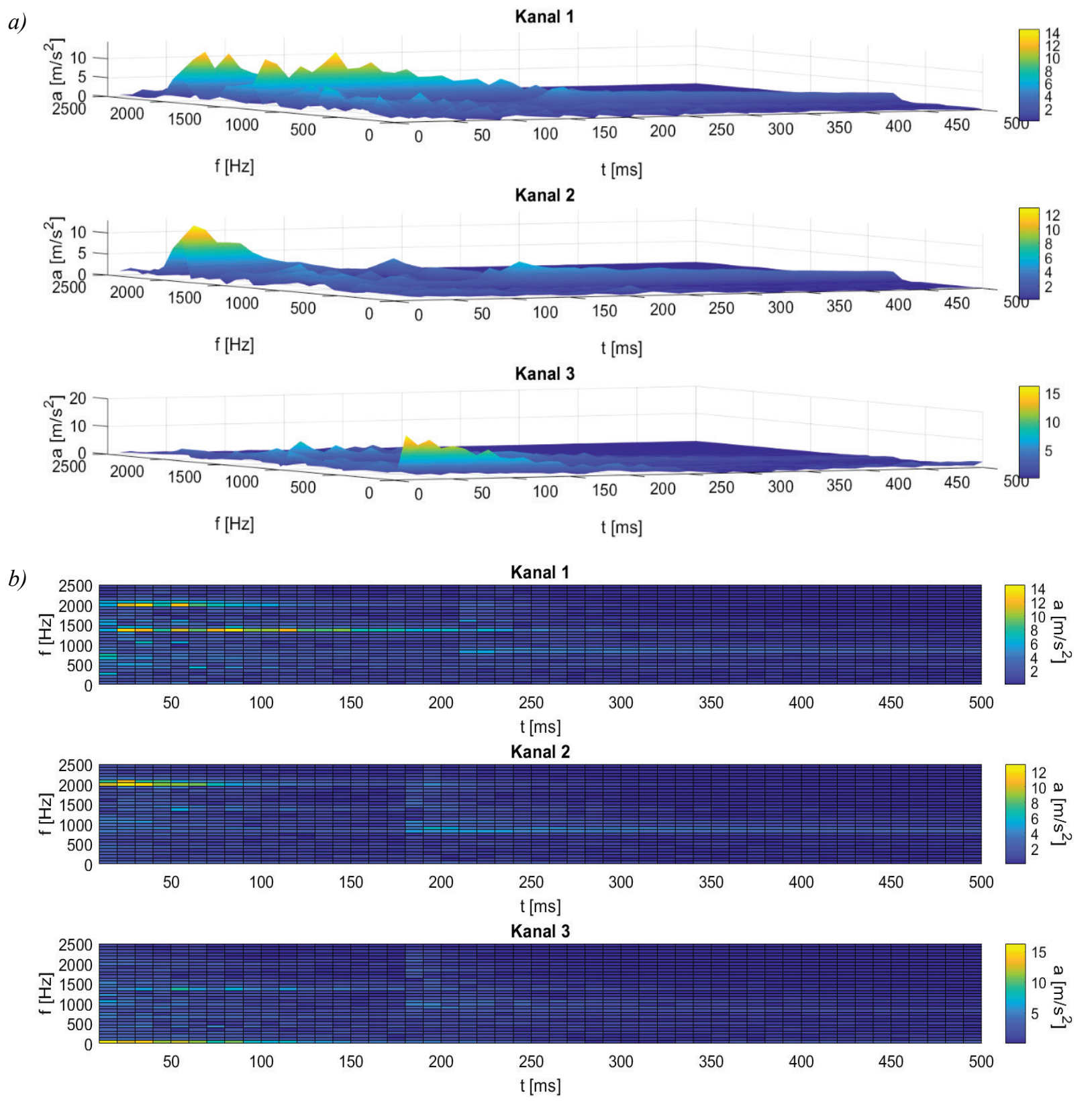

Fig. 7. a) 3D time and frequency characteristics for a plate without welded joint - P1

b) $2 D$ time and frequency characteristics for a plate without welded joint $-P 1$ 
a)

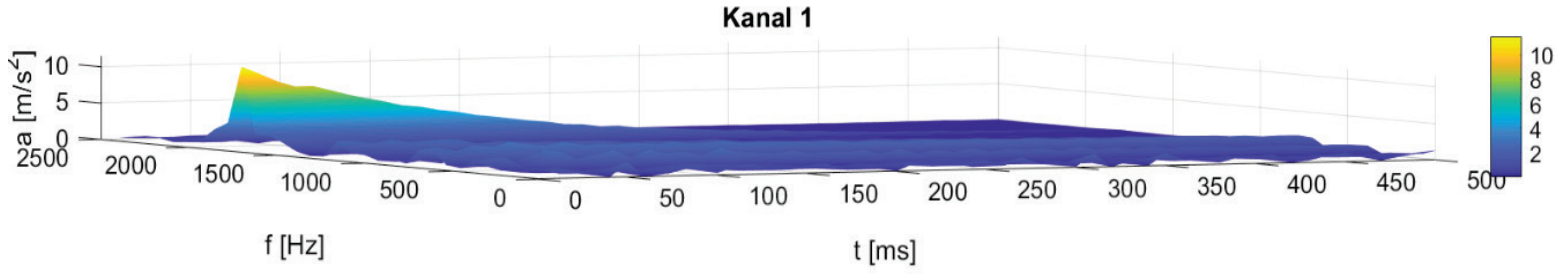

Kanal 2

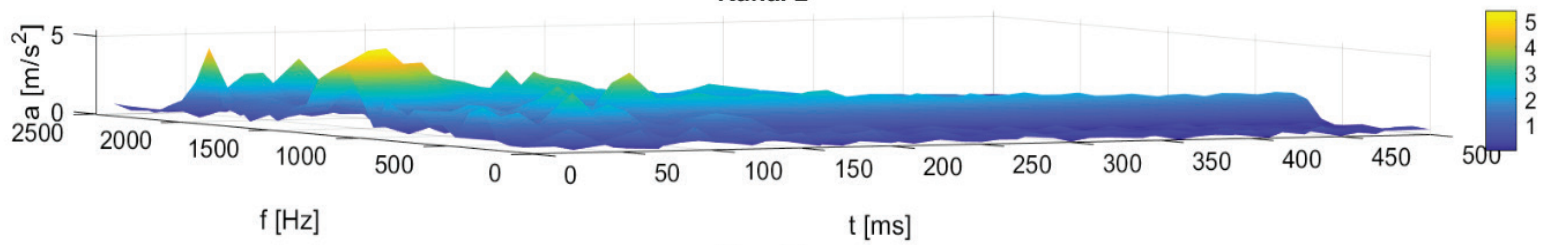

Kanal 3
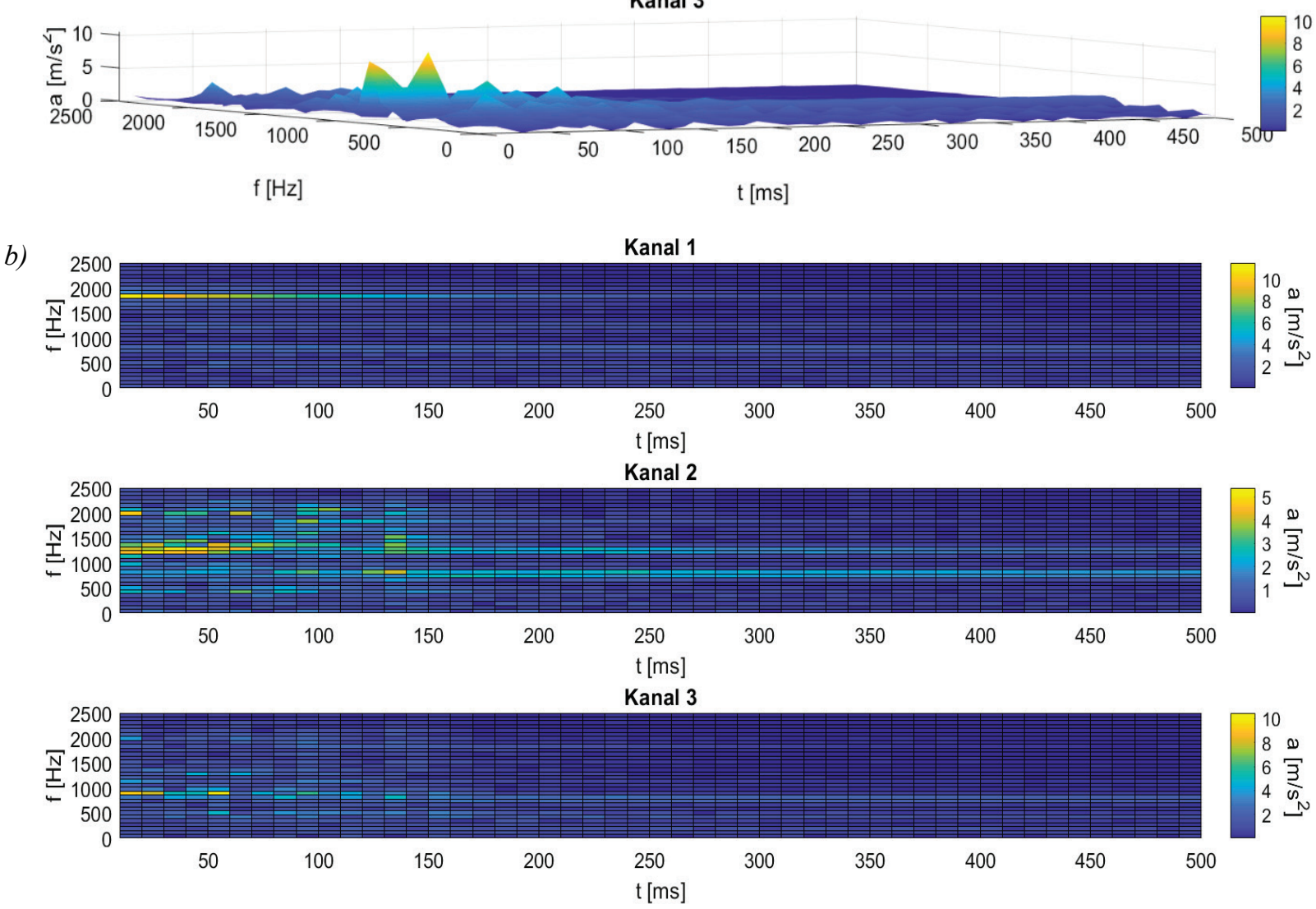

Fig. 8. a) 3D time-frequency characteristic for a welded plate with few spherical blisters in the welded joint the joint is considered acceptable - P3, b) $2 D$ time - frequency characteristic for a welded plate with few spherical blisters in the welded joint, the joint is considered acceptable - P3

The presentation of the waveforms for only three plates results from the volume limitations of this article.

\section{Conclusion}

On the basis of the comparative analysis of frequency characteristics it was found that the influence of the weld position and its state on the values of own frequencies and response amplitude is visible. This influence is also shown on the spectra in Figs. 3-6. Although the results of the frequency analysis do not allow to unequivocally assessing the quality of welded joints, they do provide data that can be used in other studies or can be used in new methods. For example, the frequency analysis itself allows determining the object's own frequencies, which can be used in simulation studies. 
a)
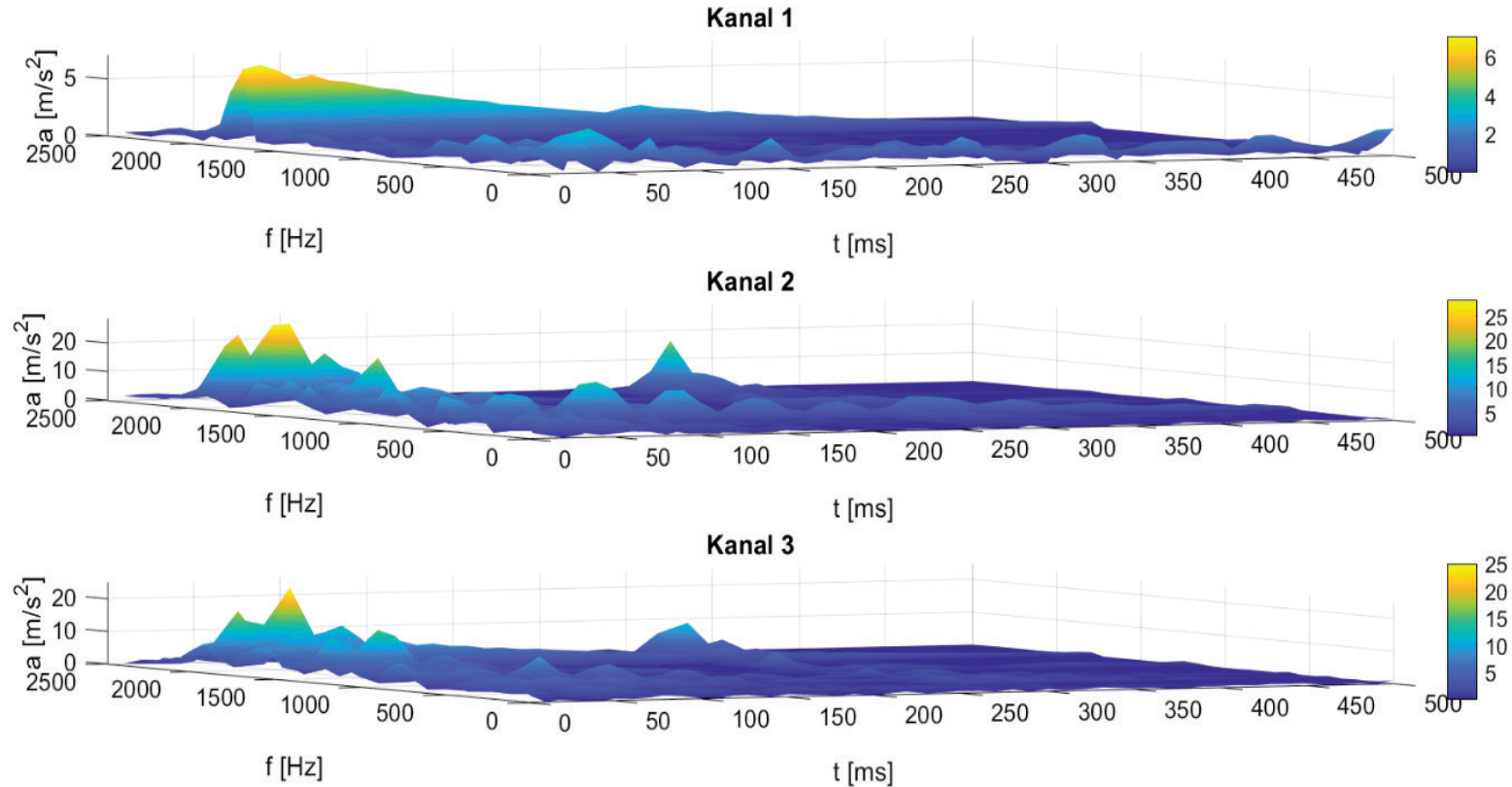

b)
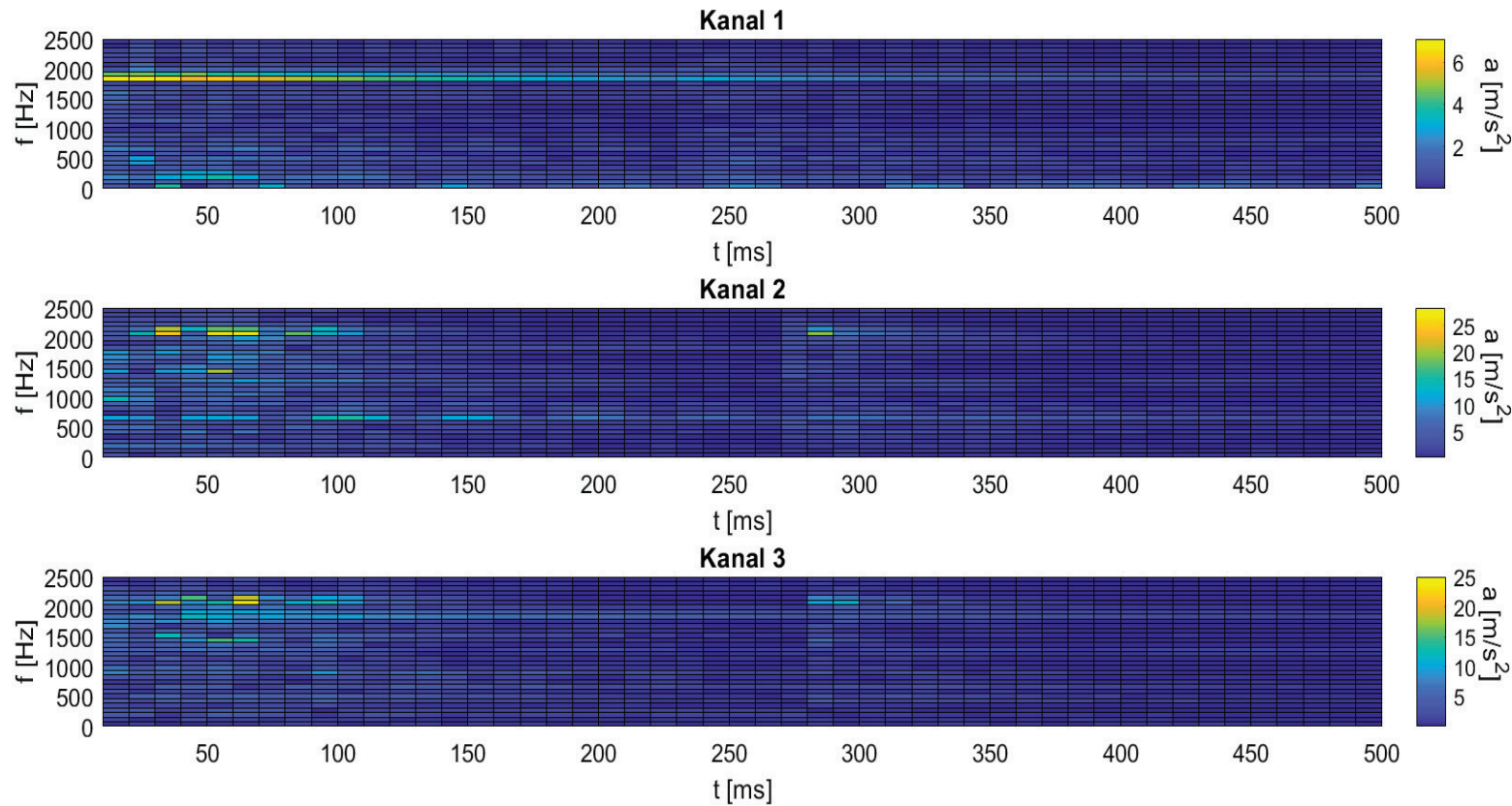

Fig. 9. a) 3D time and frequency characteristics for a plate characterized by no melting, longitudinal blister edge adhesion in a welded joint (P6), b) 2D time and frequency characteristics for a plate characterized by no melting longitudinal blister, edge adhesion in a welded joint (P6)

On the other hand, the analysis of the obtained characteristics allows, as in the first stage of the research, to conclude that the values of amplitudes and fade-away time for a plate without a welded joint are significantly higher in relation to other plates. It should be noted, however, that the interpretation of the results presented in this form in the case of plates with a smaller thickness is no longer as simple as in the case of plates that have been experimented with when testing thicker plates. The main reason for this is that there are more components than in the case of the previously presented spectra. After testing plates that are part of actual ship structures, it must be stated that the weld condition assessment method discussed in this section needs to be adapted to the specific structure (not a universal method) and requires expert evaluation, and is therefore less suitable for automatic monitoring systems of the SHM type. The methods of average distribution from time windows and logarithmic distribution of damping decrement presented in earlier papers $[11,12]$ allow for faster and more accurate determination of the state of welded joints. 


\section{References}

[1] Bruel \& Kjael Manual, https://www.bksv.com/en/Service/Calibration-and-verification/accele rometer-calibration, viewed at 24.07.2019.

[2] Hassan, M. H. A., Intelligent Manufacturing \& Mechatronics: Proceedings of Symposium, 29 January 2018, Pekan, Pahang, Malaysia (Lecture Notes in Mechanical Engineering), Springer, pp. 83-90, Malaysia 2018.

[3] Leban, J. M., Pizzi, A., Wieland, S., Zanetti, M., Properzi, M., Pichelin, F., X-ray microdensitometry analysis of vibration-welded wood, Journal of Adhesion Science and Technology, Vol. 18, Iss. 6, pp. 673-685, London 2004.

[4] Lewicka-Romicka, A., Badania nieniszczace, Podstawy defektoskopii, Wydawnictwo Naukowo-Techniczne, Warszawa 2001.

[5] Link, A., Täubner, A., Wabinski, W., Bruns, T., Elster, C., Calibration of accelerometers: Determination of amplitude and phase response upon shock excitation, Measurement Science \& Technology, Vol. 17. pp. 1888-1894, London 2006.

[6] Muc, A., Murawski, L., Szeleziński, A., Methods of cracks detection in marine structures' welded joints based on signals' time waveform analysis, Brodogradnja, Vol. 69, No. 3, pp. 43-59, Zagreb 2018.

[7] Patil, N. R., Patil, J., Non Destructive Testing (NDT) advantages and limitations, National Conference on Emerging Trends in Engineering \& Technology, At Kopargaon, Maharashtra, India 2008.

[8] Sanchez, P. S., Negro, P. L., Garcia-Fogeda, P., Vibration-based method for damage detection at welded beams and rods, Latin American Journal of Solids and Structures, São Paulo 2016.

[9] Han, S.-H., An, D.-G., Kwak, S.-J., Kang, K.-W., Vibration fatigue analysis for multi-point spot-welded joints based on frequency response changes due to fatigue damage accumulation, International Journal of Fatigue, Vol. 48, pp. 170-177, Amsterdam 2013.

[10] Szeleziński, A, Muc, A., Murawski, L., 2D and 3D time-frequency dynamic characteristics in the quality assessment of welded joint, Zeszyty Naukowe Akademii Morskiej w Szczecinie, Vol. 56, pp. 41-46, Szczecin 2018.

[11] Szeleziński, A., Muc, A., Logarytmiczny dekrement tlumienia $w$ diagnostyce połaczeń spawanych, Przegląd Spawalnictwa, Vol. 90, No. 7, pp. 13-17, Warszawa 2018.

[12] Szeleziński, A., Muc, A., Murawski, L., Quality assessment of welded joints using the mean value distribution of amplitude spectrums calculated by the time window method, Journal of KONES, Vol. 23, No. 2, pp. 263-270, Warsaw 2017.

[13] Szeleziński, A., Murawski, L., Muc., A., Gesella, G., Wybór końcówki młotka modalnego i miejsca uderzenia $w$ badaniach metoda drganiowa plyt spawanych, Zeszyty Naukowe Akademii Morskiej w Gdyni, No. 96, pp. 179, Gdynia 2016.

[14] Yaich, A., El Hami, A., Walha, L., Haddar, M., Local multiaxial fatigue damage estimation for structures under random vibrations, Finite Elements in Analysis and Design, Vol. 132, pp. 1-7, Amsterdam 2017.

Manuscript received 28 August 2019; approved for printing 03 December 2019 